\section{Feasibility of Oxygen Saturation Monitoring During Neonatal Resuscitation in Indian Scenario}

This observational study assessed the feasibility of using pulse oximeter during neonatal resuscitation in 428 term and preterm (32-36 weeks) neonates. The oxygen saturation reading was obtained by 1-minute in 152 (35.5\%) neonates. Preterm neonates and babies born by LSCS took relatively longer time for first detection of saturation.

Keywords: Evaluation, Neonatal resuscitation program, Pulse oximetry.

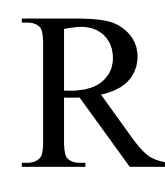

ecent neonatal resuscitation guidelines recommend routine use of pulse oximeter in neonatal resuscitation [1,2]. Conventional pulse oximeter performance during neonatal resuscitation has been variable across different studies [3]. There is paucity of Indian data addressing this issue. We aimed to assess feasibility of pulse oximeter in measuring oxygen saturation $\left(\mathrm{SpO}_{2}\right)$ after birth.

This observational study was conducted at Apollo BGS hospital, Mysore from April 2015 to April 2016. All term (37-41 weeks) and preterm (32-36 weeks) babies delivered either by caesarean section or by vaginal route, who did not require resuscitation beyond initial steps, were included. Babies with congenital anomalies and multiple pregnancies were excluded.

The time of cord clamping soon after birth was noted and oxygen saturation probe was first connected to right wrist/palm of baby. The probe was then connected to pulse oximeter (Nellcor Puritan Bennett LLC, CA, USA).. The oxygen saturation displayed along with regular plethysmograph waveform was considered accurate, and was recorded. Time of first accurate display of $\mathrm{SpO}_{2}$ value was noted. Data collected were entered into Epi info 7 database and analyzed using descriptive statistics.

A total of 428 babies (324 term) were enrolled. Only $152(35.5 \%)$ neonates out of 428 neonates had an accurate $\mathrm{SpO}_{2}$ reading at less than 1 minute of life. The median (IQR) time taken for first display of $\mathrm{SpO}_{2}$ was 63 (58-70) $\mathrm{s}$. The mean (SD) time taken for first reading in preterm babies was $64.8(7.5) \mathrm{s}$, which was significantly longer $(P=0.046)$ than in term babies (63.1 (7.4) s). The mean (SD) time taken for first reading among neonates delivered vaginally was $62.0(7.3) \mathrm{s}$ while the same in lower segment cesarean section was 64.3 (7.4) $\mathrm{s}(P=0.002)$.

We observed that only about one-third babies had $\mathrm{SpO}_{2}$ measured by one minute of age. However, nearly all babies had a stable $\mathrm{SpO}_{2}$ display before 90 s of age. These results are in agreement to earlier studies [4]. The low percentage could be due to instrument related factors or due to motion artefacts. The finding of preterm babies taking relatively longer duration than term babies for first detection of saturation as also been documented earlier [3-5]. Similarly, longer time taken for measurement in babies delivered by caesarean section has also been documented [6].

The limitation of our study was presence of dedicated personnel for probe attachment and data recording, which may not be feasible in practical situations, and which can further prolong the time taken for measurement in actual settings.

Contributors: SRK collected the data, STV contributed to writing manuscript and GG conceptualized the study and data analysis. All authors revised the manuscript and approved its final version.

Funding: None; Competing Interest: None stated.

K SUdARShan REDdy, SaINATH T VENKaTARAVANAPPa AND GIRISH GURURAJA* Department of Pediatrics, Apollo BGS Hospitals, Mysore, Karnataka, India. *drgirishg@gmail.com

\section{REFERENCES}

1. American Academy of Pediatrics and American Heart Association. Textbook of Neonatal Resuscitation. 6th edition. Elk Grove Village, IL: American Academy of Pediatrics and American Heart Association; 2011.

2. Bansal SC, Nimbalkar SM. Updated neonatal resuscitation guidelines 2015; Major changes. Indian Pediatr. 2016;53:403-8.

3. Dawson JA, Davis PG, O'donnell CP, Kamlin CO, Morley CJ. Pulse oximetry for monitoring infants in the delivery room: A review. Archives Dis Child-Fetal Neonat Ed. 2007;92:F4-7.

4. Harris AP, Sendak MJ, Donham RT. Changes in arterial oxygen saturation immediately after birth in the human neonate. J Pediatr. 1986;109:117-9.

5. Kamlin CO, O'Donnell CP, Davis PG, Morley CJ. Oxygen saturation in healthy infants immediately after birth. J Pediatr. 2006;148:585-9.

6. Hulsoore R, Shrivastav J, Dwivedi R. Normal oxygen saturation trend in healthy term newborns within 30 minutes of birth. Indian J Pediatr. 2011;78:817-20. 